\title{
Study of risk factors causing coronary heart disease among army personnel of the rank non-commissioned officers and below in the age group of 20-50 years and its association with prehypertension
}

\author{
Rajat Srivastava ${ }^{1}$, Singh R K², Bajpai R C ${ }^{3}$, Dutta P K ${ }^{1}$ \\ ${ }^{1}$ Department of Community Medicine, Armed Forces Medical College, Pune, Maharashtra, India, ${ }^{2}$ Department of Community Medicine, \\ Government Medical College, Haldwani, Nainital, Uttarakhand, India, ${ }^{3}$ Centre for Population Health Sciences, Lee Kong Chian School of \\ Medicine, Nanyang Technological University, Singapore
}

Correspondence to: Rajat Srivastava, E-mail: drrajatsrivastava27@gmail.com

Received: February 15, 2019; Accepted: March 14, 2019

\section{ABSTRACT}

Background: Coronary heart disease (CHD) is an acute public health problem both in developed and in developing countries, like India. Assessing the prevalence of CHD in the community is equivalent to assessing the tip of the iceberg. Hypertension is a major risk factor for CHD and hypertension disease prevalence tip of the iceberg in the community is much more obscure. Objective: The objective of the study was to carry out a cross-sectional study among serving Army personnel, comprising healthy non-commissioned officers and other rank personnel to successfully assess the risk factors for CHD and their association with prehypertension. Materials and Methods: Screening of risk factors for CHD among 200 randomly selected participants was carried out. Blood pressure, height, weight, serum total cholesterol, serum triglycerides, serum high-density lipoprotein (HDL), random blood sugar levels, and smoking status were the major risk factors screened. Results: Nearly $63 \%$ of Army personnel were found to be having blood pressure commensurate to the range of prehypertension. About 15\% were detected to be overweight, $22 \%$ had hypercholesterolemia, $5.4 \%$ had impaired glucose tolerance (IGT), and 19.2\% were current smokers. Higher age, body mass index, high serum triglycerides, low serum HDL, and IGT were found to be independently associated with increased prevalence of prehypertension in multiple logistic regression analysis. Conclusion: Our findings recommend the constant monitoring of CHD risk factors and the formulation of effective preventive strategies for adequate control of alarming incidence.

KEY WORDS: Coronary Heart Disease; Prehypertension; Impaired Glucose Tolerance; Body Mass Index; Non-Commissioned Officers

\section{INTRODUCTION}

Coronary heart disease (CHD) is an acute public health problem both in developed and in developing countries, like India. As per background information, CHD is now on the

\begin{tabular}{|l|c|}
\hline \multicolumn{2}{|c|}{ Access this article online } \\
\hline Website: http://www.ijmsph.com & Quick Response code \\
\hline DOI: $10.5455 /$ ijmsph.2019.0203314032019 & \\
\hline
\end{tabular}

increase in India, possibly due to the changing lifestyle, and is causing grave concern. CHD will be the most important cause of mortality in India by the year 2015 as per futuristic predictions. ${ }^{[1]}$ CHD causes more deaths annually than any other disease in the world. For CHD and stroke, unhealthy diet, physical inactivity, tobacco use, and harmful use of alcohol are the leading behavioral risk factors. For about $80 \%$ of CHD and cerebrovascular disease, behavioral risk factors are mainly the culprit for causation. ${ }^{[2]}$

Hypertension is a huge public health problem because it is frequent and an important contributor) to the epidemic of CHD, together with other risk factors including cholesterol,

International Journal of Medical Science and Public Health Online 2019. C 2019 Rajat Srivastava, et al. This is an Open Access article distributed under the terms of the Creative Commons Attribution 4.0 International License (http://creativecommons.org/licenses/by/4.0/), allowing third parties to copy and redistribute the material in any medium or format and to remix, transform, and build upon the material for any purpose, even commercially, provided the original work is properly cited and states its license. 
diabetes, and obesity, but it is modifiable. ${ }^{[3]}$ Those individuals having a systolic blood pressure in the range of $120-139 \mathrm{~mm} \mathrm{Hg}$ or diastolic blood pressure in the range of 80-89 $\mathrm{mm} \mathrm{Hg}$ should be considered as prehypertensive, thus requiring proactive health-promoting lifestyle modifications to prevent CHD. ${ }^{[4]}$ In the vast majority of populations studied, CHD is higher in people with diabetes than in those without. Lesser forms of glucose intolerance, such as impaired glucose tolerance, are also associated with higher rates of IHD. ${ }^{[3]}$ Individuals suffering from impaired glucose tolerance (IGT) and/or impaired fasting glucose have a very high risk of developing diabetes mellitus and are also susceptible to experience an adverse cardiovascular event (Myocardial Infarction, Stroke, CHD death) later in life..$^{[5]}$

The main objective of the present research study is to assess the prevalence of CHD risk factors among Army personnel of the rank non-commissioned officers (NCOs) and below in the age group of 20-50 years and its association with prehypertension.

\section{MATERIALS AND METHODS}

A health awareness and screening camp were organized for Army personnel by Department of Community Medicine, Army College of Medical Sciences (ACMS), Delhi Cantonment on September 29, 2010, as observation of World Heart Day at Auditorium of ACMS and Base Hospital, Delhi Cantonment for next 2 consecutive days. In Army, there is a welfare organization, called Army Wives Welfare Association which constantly monitors and supervises optimal health care of all Army families and their husbands who are serving in the Army. Periodically, health promotion, specific protection, and screening programs are conducted to ensure the optimal health status of all soldiers. Uniform instructions for screening were given from the medical branch of Delhi Area Headquarters after obtaining requisite go-ahead (Ethical Approval and concurrence) from the wife of Delhi Area Commander. Army personnel of the rank NCO and below in the age group of 20-50 years were included in the study. All eligible individuals were interviewed after obtaining informed consent to suffice the requirement of Ethical Approval. Information about their age in completed years, education, occupation, tobacco use, pattern of alcohol consumptionm and daily physical activity were recorded in a pre-tested pro forma. Individuals having CHD, hypertension, and diabetes were excluded at the inception stage of the research study to avoid distortion in results; however, simultaneously, it was adequately ensured that all such ailing individuals were under required therapeutic management, thus further ensuring impugning of ethical criteria in the present research study.

Assuming the prevalence of CHD to be $7 \%,{ }^{[6]}$ with $95 \%$ level of confidence and 5\% absolute error and assuming the design effect of 1.5 for the systematic sampling with $10 \%$ non-response rate, the sample size was calculated to be 172. During this period, 634 eligible participants attended the camp and out of these 200 personnel were subjected to screening for various risk factors of CHD.

The blood pressure of eligible participants was measured in the lying position after giving them a rest of $5 \mathrm{~min}$. Prehypertension was labeled when the systolic blood pressure was found to be in the range of $120-139 \mathrm{mmHg}$ or the diastolic blood pressure was found to be in the range of $80-89 \mathrm{mmHg}$, following the guidelines prescribed by "The seventh report of the joint national committee on prevention, detection, evaluation, and treatment of high blood Pressure."[4]

Body weight of eligible participants was measured on a weighing scale (calibrated to measure accurately up to 100 gms) with individual standing without footwear on the weighing scale with feet about $15 \mathrm{~cm}$ apart, thus equally distributing weight on both lower limbs. Anthropometric rod was used to measure the height of eligible participants, with their head positioned straight in standing position, so that the top of the external auditory meatus of both the ears was level with the inferior margin of both the bony orbits of eyes. The body mass index (BMI) was calculated by dividing the weight of the individual in $\mathrm{kgs}$ by the square of the height of the individual in meters. The individual was labeled overweight when BMI was $\geq 23 \mathrm{Kg} / \mathrm{m}^{2}{ }^{\left[{ }^{[7]}\right.}$ Waist circumference was measured at the level of umbilicus up to the nearest $0.1 \mathrm{~cm}$. Hip circumference was measured to the nearest $0.1 \mathrm{~cm}$ at bilateral greater trochanter level. As a moderate-intensity aerobic activity of at least $150 \mathrm{~min}$ a week ( $2 \mathrm{~h}$ and $30 \mathrm{~min}$ ), lowers the risk for these diseases, details of physical activity of the individual in his daily routine life were also enquired. ${ }^{[8]}$

When total cholesterol was $>200 \mathrm{mg} \%$, the individual was labeled to be having hypercholesterolemia and when triglycerides were $>150 \mathrm{mg} \%$, then the individual was labeled to be having hypertriglyceridemia. Low high-density lipoprotein (HDL) was labeled when HDL was $<40 \mathrm{mg} \%{ }^{[9]}$

Random Blood Sugar (RBS) level of $8-<11 \mathrm{mmol} / \mathrm{L}$ was classified as IGT, while RBS of $\geq 11 \mathrm{mmol} / \mathrm{L}$ was labeled as diabetic. ${ }^{[10]}$ All eligible participants with an $\mathrm{RBS}$ of $\geq 8 \mathrm{mmol} / \mathrm{L}$ were labeled to be having an undesirable blood sugar level and were referred for further detailed investigations and required necessary treatment.

Data were entered and coded in MS Excel 2007 and presented in percentage. Descriptive statistics such as mean, Standard Deviation(SD) were used to check the nature of data. Student's $t$-test and Chi-square test were applied to check the statistical significance. $P<0.05$ was taken as the significance level. Further multiple logistic regression analysis was employed to determine the relationship between prehypertension and risk factors of CHD. SPSS version 18 was used to conduct the required statistical analysis. 


\section{RESULTS}

The study population comprised 200 participants of the rank NCOs and below. The average age of 200 participants was $34.6 \pm 7.8$ years $($ mean $\pm \mathrm{SD})$.

Table 1 depicts mean and SD of understudy risk factors. The average systolic blood pressure of the study population was $128.0 \pm 9.0 \mathrm{~mm} \mathrm{Hg}$ which was in the prehypertensive range whereas the average values of BMI $\left(\mathrm{kg} / \mathrm{m}^{2}\right)(22.7 \pm 2.8)$, total cholesterol $(\mathrm{mg} / \mathrm{dl})(193.7 \pm 14.8)$, serum triglycerides $(\mathrm{mg} / \mathrm{dl})(145.1 \pm 7.8)$, and blood sugar $(\mathrm{mg} / \mathrm{dl})(119.3 \pm 9.8)$ were below the standard cutoff values.

Table 2 depicts the prevalence of various CHD risk factors among army personnel of the rank NCOs and below. Prevalence of prehypertension was about 63.0\% (95\% confidence interval [CI]: 56.3-69.7). HDL levels of $<40 \mathrm{mg} / \mathrm{dl}$ were found in $68 \%$ of the total group, but still, a prevalence of raised total cholesterol and triglycerides was found to be $22 \%$ and $15.3 \%$, respectively. The prevalence of IGT was seen in $5.4 \%$ of individuals. $19.2 \%$ of the eligible participants were smoking concurrently and $3.4 \%$ were consuming alcohol to the extent of 3 pegs/week. Most of the eligible participants

Table 1: Age, clinical, and laboratory test findings of the study population

\begin{tabular}{lcc}
\hline Background characteristics $(\boldsymbol{n}=\mathbf{2 0 0})$ & Mean \pm SD & $\mathbf{9 5 \%}$ CI \\
\hline Age (in years) & $34.6 \pm 7.8$ & $33.5-35.7$ \\
BMI $\left(\mathrm{kg} / \mathrm{m}^{2}\right)$ & $22.7 \pm 2.8$ & $22.3-23.1$ \\
Waist hip ratio & $0.85 \pm 0.05$ & $0.84-0.86$ \\
Systolic BP $(\mathrm{mm} \mathrm{Hg})$ & $128.0 \pm 9.0$ & $126.8-129.3$ \\
Diastolic BP $(\mathrm{mm} \mathrm{Hg})$ & $80.0 \pm 8.0$ & $78.9-81.1$ \\
Total cholesterol $(\mathrm{mg} / \mathrm{dl})$ & $193.7 \pm 14.8$ & $191.6-195.7$ \\
Serum HDL $(\mathrm{mg} / \mathrm{dl})$ & $38.8 \pm 3.7$ & $38.3-39.3$ \\
Serum triglycerides $(\mathrm{mg} / \mathrm{dl})$ & $145.1 \pm 7.8$ & $144.0-146.2$ \\
Blood sugar $(\mathrm{mg} / \mathrm{dl})$ & $119.3 \pm 9.8$ & $117.9-120.6$ \\
\hline
\end{tabular}

HDL: High-density lipoprotein, BMI: Body mass index,

CI: Confidence interval indulged into moderate or heavy exercise except for $7.6 \%$ who only indulged into light exercising.

Statistical analysis with the help of multiple logistic regression analysis showed the association of prehypertension with $\mathrm{BMI}>23 \mathrm{~kg} / \mathrm{m}^{2}$ (odds ratio [OR] 1.76, 95\% CI:1.12-2.91, $P=0.044)$, serum HDL cholesterol $<40 \mathrm{mg} / \mathrm{dl}(\mathrm{OR} 1.58,95 \%$ CI:1.08-3.21, $P=0.047)$, serum triglyceride $>150 \mathrm{mg} / \mathrm{dl}$ (OR 2.83, 95\% CI:1.98-6.11, $P=0.024$ ), for age group 30-40; $(\mathrm{OR}=2.67,95 \% \mathrm{CI}: 1.54-4.22, P<0.001)$ and for age group 40-50; $(\mathrm{OR}=4.12,95 \% \mathrm{CI}$ : 2.89-5.43, $P<$ $0.001)$, and RBS $126-180 \mathrm{mg} / \mathrm{dl}(\mathrm{OR}=2.59$; $\mathrm{CI}=1.87-6.32$, $P=0.03)$ [Table 3].

\section{DISCUSSION}

The research study found a high prevalence of prehypertension in serving Army personnel, comprising healthy NCOs and other rank personnel which is a serious cause for concern as these individuals stand a high risk of developing hypertension and CHD in later life. Statistical analysis with the help of multiple logistic regression analysis showed the association of prehypertension with BMI $>23 \mathrm{~kg} / \mathrm{m}^{2}$, serum HDL cholesterol $<40 \mathrm{mg} / \mathrm{dl}$, serum triglyceride $>150 \mathrm{mg} / \mathrm{dl}$, and RBS 126-180 mg/dl.

The prevalence of prehypertension observed in this research study was much higher than the estimates reported by other studies. Yadav et al. in their study conducted in an affluent North Indian population found the prevalence of prehypertension to be $36 \%$ in males. ${ }^{[11]}$ Singh et al. found a prevalence of prehypertension among males to be in a range of $23.5-35.1 \%$ in their research study conducted concurrently in five different cities of India. ${ }^{[12]}$ Shanthirani et al. reported a $47 \%$ prevalence of prehypertension among urban residents in Chennai who were $>18$ years, ${ }^{[13]}$ while in a survey in an industrial population, Prabhakaran et al. reported prehypertension in $44 \% .{ }^{[14]}$ Prevalence of prehypertension was $41.44 \%$ in the study by Sansanayudh et al. among Thai Army personnel ${ }^{[15]}$ and $32.9 \%$ in the study by Heydari et al.

Table 2: Distribution of behavioral and clinical parameters as a risk factor

\begin{tabular}{|c|c|c|c|}
\hline \multirow[t]{2}{*}{ Parameters } & \multirow[t]{2}{*}{$n(\%)$} & \multicolumn{2}{|c|}{$95 \% \mathrm{CI}$} \\
\hline & & Lower limit & Upper limit \\
\hline Prehypertension & $126(63.0)$ & 56.3 & 69.7 \\
\hline Serum cholesterol $>200 \mathrm{mg} / \mathrm{dl}$ & $44(22.0)$ & 16.3 & 27.8 \\
\hline $\mathrm{HDL}<40 \mathrm{mg} / \mathrm{dl}$ & $136(67.8)$ & 61.3 & 74.3 \\
\hline Serum triglycerides $>150 \mathrm{mg} / \mathrm{dl}$ & $31(15.3)$ & 10.3 & 20.3 \\
\hline RBS $126-200 \mathrm{mg} / \mathrm{dl}$ & $11(5.4)$ & 2.3 & 8.5 \\
\hline $\mathrm{BMI}>23 \mathrm{Kg} / \mathrm{m}^{2}$ & $31(15.4)$ & 10.4 & 20.3 \\
\hline Current smoking & $38(19.2)$ & 13.8 & 24.7 \\
\hline Alcohol (> 3 pegs/week) & $7(3.4)$ & 0.9 & 6.0 \\
\hline No moderate/heavy exercise & $14(7.0)$ & 3.5 & 10.5 \\
\hline
\end{tabular}

HDL: High-density lipoprotein, BMI: Body mass index, RBS: Random blood sugar, CI: Confidence interval 
Table 3: Relationship between prehypertension and various risk factors by multiple logistic regression analysis

\begin{tabular}{|c|c|c|c|}
\hline \multirow[t]{2}{*}{ Variables } & \multicolumn{3}{|c|}{ Prehypertension } \\
\hline & Risk Ratio & $95 \%$ CI & $P$-value \\
\hline \multicolumn{4}{|c|}{ Age group (in years) } \\
\hline $20-30$ & 1 (Ref) & & \\
\hline $30-40$ & $2.67 * *$ & $1.54-4.22$ & 0.001 \\
\hline $40-50$ & $4.12 * *$ & $2.89-5.43$ & 0.001 \\
\hline \multicolumn{4}{|l|}{ BMI } \\
\hline$<23 \mathrm{~kg} / \mathrm{m}^{2}$ & 1 (Ref) & & \\
\hline$>23 \mathrm{~kg} / \mathrm{m}^{2}$ & $1.76^{*}$ & $1.12-2.91$ & 0.044 \\
\hline \multicolumn{4}{|c|}{ Serum triglycerides } \\
\hline$<150 \mathrm{mg} / \mathrm{dl}$ & 1 (Ref) & & \\
\hline$>150 \mathrm{mg} / \mathrm{dl}$ & $2.83 *$ & $1.98-6.11$ & 0.024 \\
\hline \multicolumn{4}{|l|}{ Total cholesterol } \\
\hline$<200 \mathrm{mg} / \mathrm{dl}$ & 1 (Ref) & & \\
\hline$>200 \mathrm{mg} / \mathrm{dl}$ & 0.47 & $0.11-4.32$ & 0.345 \\
\hline \multicolumn{4}{|l|}{ Serum HDL } \\
\hline$>40 \mathrm{mg} / \mathrm{dl}$ & 1 (Ref) & & \\
\hline$<40 \mathrm{mg} / \mathrm{dl}$ & $1.58^{*}$ & $1.08-3.21$ & 0.047 \\
\hline \multicolumn{4}{|l|}{ RBS } \\
\hline$<126 \mathrm{mg} / \mathrm{dl}$ & 1 (Ref) & & \\
\hline $126-180 \mathrm{mg} / \mathrm{dl}$ & $2.59 *$ & $1.87-6.32$ & 0.03 \\
\hline
\end{tabular}

$* P<0.05, * * P<0.01$. HDL: High-density lipoprotein, BMI: Body

mass index, CI: Confidence interval

among military personnel in Southern Iran. ${ }^{[16]}$ Datta et al. found the prevalence of hypertension to be $32.5 \%$ in 916 men ( policemen $=507$, civilian $=409)$, randomly selected from different regions of central Kolkata which was significantly higher when compared with the civilians. Behavioral habits and obesity indices were also higher among the policemen. Regression analysis identified age, BMI, SBP, history of parental hypertension, and consumption of smokeless tobacco as the risk factors of hypertension. ${ }^{[17]}$ Abeetha et al. found the prevalence of prehypertension highest $(55.6 \%)$ among medical students out of a total of 323 students from various courses such as medicine, engineering, and arts from a deemed university in Chennai. The prevalence of prehypertension was 1.42 times more among people with high stress, 1.8 times more among people with anxiety, and 1.5 times more among medical students which were found statistically significant. ${ }^{[18]}$

Sedentary lifestyle and obesity are important modifiable risk factors for hypertension. ${ }^{[11]}$ Among behavioral risk factors for CHD the prevalence of smoking, alcohol consumption, and sedentary lifestyle were $19.2 \%, 3.4 \%$, and $7.0 \%$, respectively. Statistical analysis with the help of multiple logistic regression analysis showed the association of prehypertension with $\mathrm{BMI}>23 \mathrm{~kg} / \mathrm{m}^{2}$ (OR 1.76, 95\% CI: 1.12- 2.91, $\left.P=0.044\right)$. Raju et al. in a cross-sectional observational study conducted on 245 police personnel working at Provincial Armed Constabulary, Sitapur, found that $77.14 \%$ of individuals were having generalized obesity and $82.04 \%$ were having abdominal obesity (AO). According to the duration of service, the majority of the individuals were obese and their association with AO was highly significant $(P=0.004)$. Nature of job showed that $82.31 \%$ of individuals having AO related to field or shift, but the association was not found to be significant. ${ }^{[19]}$ The prevalence of current smoking and alcohol consumption was seen in $25.9 \%$ of males in the study by Shivaramakrishna et al. ${ }^{[20]}$ whereas Gupta et al. in their research study observed smoking to be prevalent in $36.5 \%$ of males. ${ }^{[21]}$ Our study indicates the prevalence of IGT to be 5.4\% among serving Army personnel, comprising healthy NCOs and other rank personnel. Ramachandran et al. in their research study to assess the prevalence of diabetes and IGT, conducted concurrently in six major cities, covering all the regions of our country found the age standardized prevalence of diabetes and IGT to be $12.1 \%$ and $14.0 \%$, respectively, with no significant gender difference. ${ }^{[22]}$ In our research study independent association between higher age, BMI, high serum triglycerides, low HDL, and IGT with increased prevalence of prehypertension was adequately revealed with the conduct of required statistical analysis using multiple logistic regression analysis. Sansanayudh et al. in their study on the prevalence of prehypertensive state and other CHD risk factors in the First Infantry Regiment, The King's Own Bodyguard, observed above-mentioned factors to be associated with prehypertension. ${ }^{[15]}$ Similar findings were observed by Yadav et al. in their study where increasing age, BMI, and IGT were significantly associated with prehypertension. ${ }^{[11]}$

\section{Strength and Study Limitation}

The strength of the study was that we could successfully show the significant frequency of the risk factors in a limited number of serving Army personnel, comprising of healthy NCOs and other rank personnel, who adequately represented the general population of the serving Army personnel.

The elicited history for smoking and alcohol consumption by the eligible participants might have been less in our research study as there might have been hesitancy on the part of serving Army personnel, comprising healthy NCOs and other rank personnel to divulge such behaviors. The eligible participants in our research study were young male serving soldiers with a high level of physical fitness, endurance, and a habit of undertaking regular exercise. Although this may limit the generalization of the results to other subgroups, the present findings are consistent with findings from other studies involving different subgroup of people. In addition, the classification of prehypertension was based on only one measurement of blood pressure and cannot exclude the apprehension caused by a doctor to an unsuspecting healthy individual while examining (white coat phenomenon), which could have resulted in finding a higher prevalence of prehypertension. However, most of the other epidemiological studies used the same method of measurement making the present method justifiable for comparison. By these 
results we cannot generalize our conclusion about increasing or decreasing trend of foregoing risk factors among serving Army personnel, comprising of healthy NCOs, and other rank personnel. Therefore, we strongly recommend the conduct of future prospective multicenter investigations to have clear estimates for future interventions and implementation of preventive strategies.

\section{CONCLUSION}

Our research study adequately demonstrates that the prevalence of prehypertension and other CHD risk factors are high among serving Army personnel, comprising healthy NCOs and other rank personnel. It is therefore very strongly recommended that all other rank personnel should also be subjected to a detailed medical examination with focus on screening for CHD risk factors. The Army Officers undergo detailed medical examination periodically every five years, subsequent to attaining the age of 35 years Periodic Medical Examination (PME). The Army Junior Commissioned Officers also undergo, PME once within one year of promotion or after attaining the age of 40 years, but before attaining the age of 41 years. Similarly, in the civilian population, everyone should undergo PME, periodically every 5 years, subsequent to attaining the age of 35 years. Further, research studies should be encouraged to assess the effect of lifestyle modification on CHD morbidity and mortality.

\section{REFERENCES}

1. Venkatramana P, Reddy PC. Association of overall and abdominal obesity with coronary heart disease risk factors: Comparison between urban and rural men Asia Pacific. J Clin Nutr 2002;11:66-71.

2. Cardiovascular diseases (CVDs). World Health Organization. 2012. Available from: http://www.who.int/mediacentre/ factsheets/fs317/en/index.html. [Last cited on 2012 Aug 30].

3. Cook GC, Zumla AI. Manson's Tropical Diseases. $22^{\text {nd }}$ ed. London: WB Saunders Elsevier Ltd.; 2009. p. 672-3.

4. Chobanian AV, Bakris GL, Black HR, Cushman WC, Green LA, Izzo JL Jr., et al. The seventh report of the joint national committee on prevention, detection, evaluation, and treatment of high blood pressure: The JNC 7 report. JAMA 2003;289:2560-71.

5. DeFronzo RA, Abdul-Ghani M. Assessment and treatment of cardiovascular risk in prediabetes: Impaired glucose tolerance and impaired fasting glucose. Am J Cardiol 2011;108:3B-24B.

6. Shah B, Mathur P. Surveillance of cardiovascular disease risk factors in India: The need and scope. Indian J Med Res 2010;132:634-42.

7. Snehalatha C, Viswanathan V, Ramachandran. Cutoff values for normal anthropometric variables in Asian Indian adults. Diabetes Care 2003;26:1380-4.

8. Available from: http://www.cdc.gov/physicalactivity/everyone/ health/index.html. [Last accessed on 2019 Jan 05].

9. Reddy K, Rao A, Reddy T. Socioeconomic status and the prevalence of coronary heart disease risk factors. Asia Pac J Clin Nutr 2002;11:98-103.
10. Amplavanar NT, Gurpreet K, Salmiah MS, Odhayakumar N. Prevalenceofcardiovasculardiseaseriskfactorsamongattendees of the batu 9, cheras health centre, Selangor, Malaysia. Med J Malaysia 2010;65:166-72.

11. Yadav S, Boddula R, Genitta G, Bhatia V, Bansal B, Kongara $S$, et al. Prevalence and risk factors of pre-hypertension and hypertension in an affluent north Indian population. Indian J Med Res 2008;128:712-20.

12. Singh RB, Fedacko J, Pella D, Macejova Z, Ghosh S, de Amit K, et al. Prevalence and risk factors for prehypertension and hypertension in five Indian cities. Acta Cardiol. 2011;66:29-37.

13. Shanthirani CS, Pradeepa R, Deepa R, Premalatha G, Saroja R, Mohan V. Prevalence and risk factors of hypertension in a selected South Indian population-the Chennai urban population study. J Assoc Phys India 2003;51:20-7.

14. Prabhakaran D, Shah P, Chaturvedi V, Ramakrishnan L, Manhapra A, Reddy K. Cardiovascular risk factor prevalence among men in a large industry of Northern India. Natl Med J India 2005;18:59-65.

15. Sansanayudh N, Luvira V, Woracharoensri N, Phulsuksombati D, Sripen R. Prevalence of prehypertensive state and other cardiovascular risk factors in the first infantry regiment, the king's own bodyguard. J Med Assoc Thai 2009;92:S28-38.

16. Heydari S, Khoshdel A, Sabayan B, Abtahi F, Zamirian M, Sedaghat S. Prevalence of cardiovascular risk factors among military personnel in Southern Iran. Iran Cardiovasc Res J 2010;4:22-7.

17. Datta G, Sen A, Das M, Basu S. Prevalence of hypertension and its associated risk factors among Kolkata-based policemen: A sociophysiological study. Int J Med Sci Public Health 2015;4: 225-32.

18. Abeetha S, Sureka V, Brinda S, Ganesh M, Olickal JJ, Sujatha. Prevalence of prehypertension and its association with levels of stress and anxiety among students of various disciplines in Chennai - a cross-sectional study. Natl J Physiol Pharm Pharmacol 2018;8:1599-604.

19. Raju S, Tiwari S, Verma NS, Kumari R. Prevalence of generalized and abdominal obesity in police worker a crosssectional study. Int J Med Sci Public Health 2017;6:1674-8.

20. Shivaramakrishna HR, Wantamutte AS, Sangolli HS, Mallapur MD. Risk factors of coronary heart disease among bank employees of Belgaum city-cross-sectional study. Al Am En J Med Sci 2010;3:152-9.

21. Gupta R, Gupta VP, Sarna M, Bhatnagar S, Thanvi J, Sharma V, et al. Prevalence of coronary heart disease and risk factors in an urban Indian population: Jaipur heart watch-2. Indian Heart J 2002;54:59-66.

22. Ramachandran A, Snehalatha C, Kapur A, Vijay V, Mohan V, Das AK, et al. High prevalence of diabetes and impaired glucose tolerance in India: National urban diabetes survey. Diabetologia 2001;44:1094-1.

How to cite this article: Srivastava $R$, Singh RK, Bajpai RC, Dutta PK. Study of risk factors causing coronary heart disease among army personnel of the rank non-commissioned officers and below in the age group of 20-50 years and its association with prehypertension. Int J Med Sci Public Health 2019;8(5):360-364.

Source of Support: Nil,Conflict of Interest: None declared. 